\title{
CERNUdA Y LA LENGUA POÉTICA: UNA REVISIÓN INTENCIONADA DE LA POESÍA ESPAÑola
}

\author{
LUIS GÓMEZ CANSECO \\ Universidad de Huelva
}

La inclusión de Las Nubes en la segunda edición de La Realidad y el Deseo, publicada en México en 1940, y la coincidencia temporal con el inicio del exilio inglés de Luis Cernuda han contribuido a determinar el camino que la crítica siguió en el estudio de su evolución poética. Tampoco fueron ajenas a este hecho las declaraciones del propio Luis Cernuda en Historial de un libro, una reconstrucción tardía e interesada de su vida literaria, en la que había declarado, refiriéndose a este período: «La estancia en Inglaterra corrigió y completó algo de lo que en mí y en mis versos requería dicha corrección y compleción» ${ }^{1}$. Sobre estas premisas, Octavio Paz estableció dos etapas para la poesía de Cernuda en su ensayo «La palabra edificante»: la «poesía de juventud,» que llegaría hasta Invocaciones, y los «libros de madurez», entre los que ya se incluye Las Nubes ${ }^{2}$. La idea arraigó decisivamente en la crítica cernudiana, y así la encontramos repetida en Manuel Ulacia, Agustín Delgado, Philip Silver, Victoria Utrera o en Eloy Sánchez Rosillo, que señala:

... en los seis primeros libros de La realidad y el deseo, es decir, en los libros escritos antes de 1937, se observa una gran diversidad, una constante evolución; por el contrario, en las cinco secciones restantes, desde Las nubes

1 Cernuda, Luis, Prosa I. Obra Completa, ed. de Derek Harris y Luis Maristany, Madrid, Siruela, 1994, p. 645. En adelante, $P$ I, y $P$ II para el segundo volumen, Cernuda, Luis, Prosa II. Obra Completa, ed. de Derek Harris y Luis Maristany, Madrid, Siruela, 1994. No se olvide que Historial de un libro empezó a gestarse ya en México y al hilo de unas conversaciones con el periodista Emmanuel Carballo, que irían saliendo en el semanario México en la cultura a lo largo del año 1958.

2 PAZ, Octavio, «La palabra edificante», en HARRIS, DEREK (ed.), Luis Cernuda, Madrid, Taurus, 1977 , p. 141. La primera versión salió en Papeles de Son Armadans en 1964. 
hasta Desolación de la Quimera, se advierte un tono sostenido y uniforme. La poesía de Luis Cernuda, una vez llegado el poeta a la madurez, apenas evoluciona ${ }^{3}$.

No es necesario acudir a apreciaciones literarias para ver en buena parte de los poemas de Las Nubes, como «Noche de luna», «A un poeta muerto», «Scherzo para un elfo» o «Soñando la muerte», el espíritu, la temática y las formas de Invocaciones. $\mathrm{Y}$ es que, en realidad, el verdadero cambio, el que marcó el inicio de una poética esencialmente nueva para Cernuda, lo encontramos en Como quien espera el Alba, libro al que se refería como «una de las colecciones de mis versos donde más cosas hay que prefiero» $(P I, 648)$. La obra se escribió entre Oxford, Glasgow y Cambridge desde el verano de 1941 hasta la primavera de 1944, y, como siempre en la historia literaria, las fechas tienen una importancia radical.

James Valender subraya el considerable e interesante impacto que la tercera edición de La Realidad y el Deseo (1958) tuvo entre la crítica literaria mexicana ${ }^{4}$. Entre las reseñas más significativas que se publicaron con ese motivo, apareció una en la Revista Mexicana de Literatura en la que Tomás Segovia cargaba duramente contra el pretendido coloquialismo que se asentó en la obra de Cernuda a partir de Como quien espera el Alba:

Luis Cernuda ha sido uno de los casos más claros de voz poética. Lo que ha habido siempre en su mejor poesía ha sido eso: voz, indefinible acento, ritmo pero no insistente, sino tierno y ahogado como de agua murmurante... . Para mí ese tono se mantiene más o menos constante hasta Las nubes y empieza a flaquear en Como quien espera el alba. ...Lo que domina en estos libros es un tipo de poesía que ni siquiera es agresivamente prosaico, sino de una irremediable vulgaridad. Comprendo que esta vulgaridad es voluntaria... . En largos versos que uno no se atreve a llamar coloquiales (porque afortunadamente la gente no habla así), arrítmicos, carentes de imágenes, hechos de un lenguaje incoloro de periodista, con absurdas transposiciones sintácticas de ateneo de pueblo, donde incluso escatima los artículos para dar mayor sequedad de estilo notarial, el autor nos cuenta, tal como podemos encontrarlos en la página literaria de un periódico de provincias, algunos episodios de historia literaria o de historia a secas ${ }^{5}$.

En su crítica, Segovia resumía los rasgos de esa transformación estilística: vulgaridad voluntaria, sequedad y episodios de historia. También Derek

\footnotetext{
${ }^{3}$ La fuerza del destino. Vida y poesía en Luis Cernuda, Murcia, Universidad de Murcia, 1992, p. 88.

4 Cfr. VALENDER, James, «Cernuda en México: El poeta ante la crítica mexicana», en Actas del Primer Congreso Internacional sobre Luis Cernuda (1902-1963), Sevilla, Universidad de Sevilla, 1990, pp. 102-105.

5 «La Realidad y el Deseo», en HARRIS, Derek (ed.), Luis Cernuda, Madrid, Taurus, 1977 , p. 53. La reseña se publicó en el número 1 de 1959 , correspondiente al primer trimestre del año.
} 
Harris situó el cambio poético de Cernuda entorno al año 1942, coincidiendo con la primera edición de Ocnos: «Aquel momento del primer Ocnos representa la conclusión de una etapa que luego deja lugar al comienzo de otra». Y precisa aún más al afirmar que el poeta se aleja entonces y cada vez más de «la visión romántica del mundo, proceso que culmina en su último libro de poemas, Desolación de la Quimera» ${ }^{6}$. Fue también en esas fechas cuando Cernuda empezó a preocuparse por la teoría del lenguaje literario, una cuestión que sería crucial para su propia literatura. Así lo describía en Historial de un libro:

\begin{abstract}
...acostumbrado al ornato verbal, barroco en gran parte, de la poesía española, que de manera más sutil me parecía repetirse en la francesa, me desconcertaba no hallarlo en la inglesa o, al menos, que ésta no hiciera del mismo, como los españoles y los franceses, razón de ser para la poesía. Pronto hallé en los poetas ingleses algunas características que me sedujeron: el efecto poético me pareció mucho más hondo si la voz no gritaba ni declamaba, ni se extendía reiterándose, si era menos gruesa y ampulosa. La expresión concisa daba al poema contorno exacto, donde nada faltaba ni sobraba, como en aquellos epigramas admirables de la antología griega. $(P I, 646)$.
\end{abstract}

La búsqueda de una expresión concisa no nació sólo al hilo de la creación poética, sino también, y creo que muy determinantemente, como consecuencia de la labor crítica y docente que Cernuda acababa de iniciar. Junto al progresivo conocimiento de la crítica poética inglesa, en esos años se entregó a conciencia a la preparación de su docencia universitaria, y llegó incluso a confesar a Nieves Madariaga, como recuerda Martínez Nadal, su intención de ahondar en la carrera académica ${ }^{7}$. De hecho, si el contacto con la poesía inglesa fue causa del cambio que se produjo en su poesía, también lo fue, y no en menor medida, el estudio obligado de la historia de la poesía española y la reflexión que se siguió de este trabajo escolar.

Las primeras consecuencias críticas de la labor docente fueron dos ensayos recogidos luego en Poesía y Literatura, y compuestos, al menos en su versión original, en enero de 1941, «Poesía popular» y «Tres poetas clásicos». En el primero ellos, Cernuda negaba la existencia de la poesía popular, argumentando que «poesía» y «popular» eran términos antitéticos:

La expresión poesía popular, o la de arte popular, es en realidad un contrasentido, porque la esencia misma de la poesía y del arte están en contradicción con lo que el pueblo representa; el pueblo es pueblo de un modo indistinto y colectivo, y la poesía exige como condición previa para acercarse a

6 La poesía de Luis Cernuda, Granada, Universidad de Granada, 1992, pp. 13-14.

7 Cfr. Martínez NAdAL, Rafael, Españoles en la Gran Bretaña. Luis Cernuda. El hombre y sus temas, Madrid, Hiperión, 1983, p. 125. 
ella la singularidad (y por singular entiendo algo bien diferente de lo personal), lo cual es incompatible con lo colectivo. (P $I, 483-484)$

Citando a Juan Ramón Jiménez, Cernuda explicaba la poesía popular como «imitación o tradición inconsciente de un arte refinado que se ha perdido» $(P I, 483)$. Frente al concepto de literatura popular oral que dominaba en la época y que se había generado en los estudios sobre la literatura medieval, propuso una redefinición del término basada en el prefacio a las Lyrical Ballads, donde William Wordsworth manifestaba su creencia en la posibilidad de elaborar un lenguaje poético que sólo se diferenciara de la prosa en lo referente a la métrica:

The majority of the following poems are to be considered as experiments. They were written chiefly with a view to ascertain how far the language of conversation in the middle and lower classes of society is adapted to the purposes of poetic pleasure ${ }^{8}$.

Junto al de Wordsworth, Cernuda anotó el nombre de Ramón de Campoamor: «Conviene recordar que ideas muy parecidas en este punto a las de Wordsworth eran las que expresó entre nosotros Campoamor, al menos en lo que respecta a su deseo de reducir el lenguaje poético a pura prosa, sin otro diferencia que la mecánica del metro y de la rima» $(P I$, 476). Curiosamente, es la primera vez que los nombres de Wordsworth y Campoamor aparecen en la obra de Cernuda; y lo hacen unidos.

También acudió Cernuda a la poesía española en el otro ensayo fechado en 1941, «Tres poetas clásicos», donde volvió a tratar la cuestión del lenguaje poético al hablar de Garcilaso de la Vega: «Gracias al estilo las palabras del poeta son al mismo tiempo idea y emoción; es decir, no son meros sonidos elocuentes o melodiosos, sino expresión que contiene en sí una realidad, ofreciéndola clara y pura como la luz tras el cristal». Y repitió algo similar al contrastar la poesía de fray Luis de León y la de Góngora: «Góngora, temperamento antípoda del de Fray Luis de León, aunque igualmente apasionado, es más castizo en este sentido, porque utiliza poéticamente las palabras sólo hasta un límite: aquel donde terminan las posibilidades físicas de la expresión y comienzan las metafísicas» ( $P I$, 490, 493).

Cinco años después, en «Tres poetas metafísicos», volvía sobre el asunto del lenguaje literario para interrogarse sobre las Coplas a la muerte de su padre de Jorge Manrique:

¿Son brote final de una época que desaparece? ¿Son punto de partida para una época que comienza?... ¿Conocía Garcilaso las Coplas? Su amigo Juan

8 Wordsworth, William, y Samuel T. COLERIDGE, Lyrical Ballads. A Facsimile Reprint of the First Edition, Oxford, Woodstock Books, 1993, p. i. 
de Valdés las menciona en el Diálogo de la lengua, donde alude a Gracilaso y donde expone una doctrina del estilo que tiene evidente afinidad estética con el lenguaje de Manrique. Pero éste representa una forma estilística para la cual la palabra es sobre todo revelación directa de un pensamiento, sin complacerse, como ya se complace Garcilaso, en las asociaciones que la imaginación puede efectuar con la palabra, prescindiendo de su significado inmediato. $(P I, 503)$

La mención de Juan de Valdés no era casual, pues en el Diálogo de la lengua también se defendía un modelo poético basado en la lengua hablada, que tanto Campoamor como Cernuda tuvieron muy presente a la hora de elaborar su ideario poético y su propuesta de identificación entre verso y prosa: «Y siendo assí que la gentileza del metro castellano consiste en que de tal manera sea metro que parezca prosa, y que lo que se scrive se dize como se diría en prosa, tengo por buenos muchos de los romances que stan en el Cancionero general, porque en ellos me contenta aquel su hilo de dezir que va continuado y llano» ${ }^{9}$.

Este texto, y otros similares de Valdés, no debieron pasar desapercibidos a Cernuda, para quien la reforma de la lengua literaria seguía siendo un problema central de la poética. Pero no se trataba sólo de trazar una dirección crítica afín a sus propuestas, también pretendió ejemplificar ese modo poético singular en la historia de la poesía española señalando una línea que se abriría con el romancero viejo y, sobre todo, con Jorge Manrique, continuaría en Garcilaso y se quebraría en el convencionalismo de Fernando de Herrera:

El equilibrio entre lenguaje hablado y lenguaje escrito, natural a alguno de nuestros poetas medievales, tan perfectamente sostenido en Manrique, comienza en Garcilaso a romperse a favor del lenguaje escrito; y aunque ni él ni sus predecesores profesen ya como doctrina tal desequilibrio, poco a poco van alejando, en cuanto a equivalencia y correspondencia, una forma lingüística de otra. Es Herrera quien agrava dicha actitud y la codifica, haciendo del lenguaje escrito algo remoto y aun opuesto al lenguaje hablado. Hasta en Garcilaso, al que admira, ha de encontrar Herrera palabras que estima vulgares, dada su urgencia de vocablos ilustres y escogidos. $(P I, 503)^{10}$

De ese mismo año de 1946, conservamos unas notas tituladas «Acerca de mis versos». Se trata del borrador de una conferencia que Cernuda impartió el 8 de marzo en el King's College de Londres invitado por el

9 VAldÉs, Juan de, Diálogo de la lengua, ed. de Cristina Barbolani, Madrid, Cátedra, 1990, p. 244.

10 Esta última frase la recuperó Cernuda, casi literalmente, para sus Estudios sobre poesía española contemporánea, donde escribe: «Hasta en Garcilaso, maestro del lenguaje más sutil y penetrante que haya en nuestra lírica (sin que por eso pierda de vista la realidad de las cosas) halla Herrera palabras y expresiones 'vulgares' a reprochar» $(P I, 73)$. 
profesor Edward Wilson. Las anotaciones no tienen desperdicio (al menos para la historia literaria del poeta), y confirman las preocupaciones poéticas a las que Cernuda atendía por esos años. En lo que corresponde al lenguaje literario y a los estilos poéticos, apunta:

Popularismo y barroquismo: dos aspectos de un mismo fenómeno literario.
Barroco: expresión artística semiadulta de una mentalidad primitiva... . [Mi
deseo: armonizar, no exagerar (Manrique, Garcilaso, Aldana, fray Luis de León,
San Juan de la Cruz, Bécquer)]. Materia sobre la cual trabaja el poeta: el
lenguaje... Lenguaje hablado y lenguaje escrito. Equilibrio necesario entre
ambos. Necesidad de una raíz ancestral en el lenguaje ('Escribo como mi madre
hablaba', J. R. Jiménez).

En los márgenes añadió la nota siguiente: «Riesgo del lenguaje escrito, pedantería. Riesgo del lenguaje hablado, vulgaridad. Decadencia del primer extremo: Rubén Darío. Decadencia del segundo extremo: Campoamor» $(P$ II, 772-773). Aunque llegara a tacharla en el original mecanografiado, resulta especialmente interesante su propuesta poética («armonizar, no exagerar») y la ejemplificación que encuentra para ese modo poético en la tradición española; todo ello, junto con la negación del popularismo, su identificación con el barroquismo y las menciones de Rubén Darío, Campoamor y Juan Ramón Jiménez terminan de definir su propuesta poética.

En 1957 y desde otra perspectiva, Cernuda retomó este asunto en las «Observaciones preliminares» a sus Estudios sobre poesía española contemporánea. Allí hace un recorrido por la lírica española, y establece tres estilos poéticos: «cuando lenguaje hablado y lenguaje escrito coinciden, como ocurre en las Coplas de Manrique»; «cuando empiezan a divergir, como ocurre en Garcilaso»; y, por último, «cuando lenguaje hablado y lenguaje escrito se oponen, como ocurre en Góngora» $(P I, 72)$. Para Cernuda la necesidad de equilibrio entre el lenguaje hablado y el escrito no es sólo una cuestión formal, sino que surgía de los mismos contenidos y de la atención que el poeta debía a la realidad circundante: «La realidad cambia, la sociedad se transforma, ya de modo gradual, ya de modo brusco y revolucionario, y el poeta, consciente de dichas transformaciones, debe hallar expresión adecuada para comunicar en sus versos su visión diferente del mundo» $(P I, 74)$. Y es que la identificación que pretende entre lengua hablada y escrita había de tener su continuación en una temática próxima al hombre y al mundo real, pues se trataba de crear una comunidad espiritual entre el público y el poeta, que respondiese al modo de poesía popular que Wordsworth habían definido.

Pero no sólo Wordsworth. En gran medida, todas estas formulaciones tenían su origen en la Poética de Ramón de Campoamor. Para 1954, cuando escribió el capítulo dedicado a Campoamor en los Estudios sobre poesía española contemporánea, Cernuda estaba centrado en la historia de la 
poesía española, y encontró en Campoamor una voluntad de reflexión teórica compartida y una intensa atención a las razones del propio quehacer poético. Ramón de Campoamor dejó constancia de esa preocupación en su Poética, publicada 1883, pero iniciada en 1875 al hilo de unas acusaciones de plagio vertidas por Joaquín Vázquez y Muñoz en el diario El Globo. Las diversas respuestas, réplicas y contrarréplicas de don Ramón tomaron forma definitiva en la Poética. A Cernuda debió interesarle muy especialmente el capítulo $\mathrm{X}$ de la obra, donde Campoamor se preguntaba: «¿Debe haber para la poesía un dialecto diferente del idioma nacional?». La respuesta, obviamente, era no; $\mathrm{y}$, ateniéndose a ese planteamiento, Campoamor definió la poesía como «la representación lírica de un pensamiento por medio de una imagen y expresado en un lenguaje que no se pueda decir en prosa ni con más naturalidad ni con menos palabras» ${ }^{11}$. Campoamor, que defendía el equilibrio entre lo que él llamaba la auténtica lengua nacional y el verdadero lenguaje poético, también cifró en Fernando de Herrera los males de una lengua alambicada y señaló una línea poética alternativa en la lírica española:

¿Cuánto más popular y cuánto más nacional sería nuestra poesía, si, en vez de la locución artificiosa de Herrera, se hubiese cultivado este lenguaje natural de Jorge Manrique, que es la dirección que siguieron después Garcilaso, Fray Luis de León y Lope de Vega! ${ }^{12}$

Esa negativa mención de Herrera y la nómina de poetas tuvieron no poca importancia para la revisión que Cernuda pretendía hacer de la historia literaria española. Lo más probable es que Cernuda cambiara de opinión respecto a Herrera a raíz de su lectura de la Poética. Hasta entonces las menciones que encontramos al poeta sevillano son más bien elogiosas; en 1935, por ejemplo, todavía lo incluía entre «los grandes nombres de nuestra poesía anterior: Herrera, Lope, Góngora y Calderón» $(P I I, 70)$. Por otro lado, la conexión entre Jorge Manrique, Garcilaso, fray Luis y Lope de Vega también debió resultarle sugerente, pues siguió acudiendo a ella durante el resto de su vida. La primera mención que Cernuda hizo de Jorge Manrique aparecía en «Cervantes», cuya primera redacción data de 1940, cuando ya había empezado a leer a Campoamor. Lo mismo ocurre con fray Luis de León, a quien sólo se refiere en su obra crítica a partir de 1941. Garcilaso y Lope, por su parte, siguieron distintas trayectorias en el juicio cernudiano: la de Lope - de quien escribió: «la desaparición supuesta de la obra lírica de Lope ...ंalteraría en algo la trayectoria de nuestra lírica?» (P I, 694)-, descendente; la de Garcilaso, constante y ascen-

11 Campoamor, Ramón de, Poética, ed. de José L. García Martín, Gijón, Universos, 1995, p. 128.

${ }_{12}$ Ibid., p. 127. 
dente, pues siempre lo identificó como «el poeta español que más querido me es».

Lo cierto es que, cuando Cernuda pretendió ejemplificar una trayectoria poética en la poesía española en la que se hubiera mantenido el equilibrio entre lenguaje hablado y lengua literaria, repitió una y otra vez, y casi literalmente, la misma relación de poetas elaborada por Campoamor. Si en 1932 ya había establecido una conexión entre Garcilaso, san Juan de la Cruz y Bécquer, era sólo como parte de un modo de poesía que identificaba con los grandes movimientos románticos ingleses y alemanes ${ }^{13}$. Pero es en 1946, en las mencionadas notas «Acerca de mis versos,» cuando la lista de Campoamor aparece ya como ejemplo de equilibrio entre lenguaje hablado y escrito: «Manrique, Garcilaso, Aldana, fray Luis de León, San Juan de la Cruz, Bécquer». También en el diálogo satírico El crítico, el amigo y el poeta, de 1948, confesaba que, más que en los poetas franceses, descubrió su propio ámbito literario en los años previos al surrealismo «a través de los poetas españoles,» entre los que señalaba a «Manrique y Garcilaso y Aldana y fray Luis de León y San Juan de la Cruz y Quevedo y Calderón» (P I, 620-621). Y lo mismo volvió a escribir casi diez años después en Historial de un libro:

Leía entonces por primera vez, y digo por primera vez porque sólo en aquellos días percibí el sentido de lo que dejaron escrito, aunque en algunos casos fuera relectura, a los poetas españoles clásicos: Garcilaso, Fray Luis de León, Góngora, Lope, Quevedo, Calderón. (P I, 627)

No hay que recordar que entonces también leía, y con gusto - aunque pretendiera negarlo-, a Fernando de Herrera o a Francisco de Rioja. Pero fue a partir de la lectura de la Poética de Campoamor, cuando Cernuda empezó a elaborar sistemáticamente una propuesta firme sobre el lenguaje literario y una poética atenta a aproximar la poesía al hombre y a la realidad contemporánea.

$\mathrm{Su}$ intención no era meramente erudita o académica. Cernuda no se acercó a la literatura española con la asepsia de un historiador, sino con la voluntad de encontrar una voz poética propia. Su brillante labor crítica sólo se explica como una indagación en sí mismo; sus estudios de Campoamor o de Bécquer, sus ensayos sobre Juan Ramón o sobre el pensamiento lírico de Blake, Wordsworth, Coleridge y Browning, sus páginas sobre Gide, Rilke, Cervantes, Yeats, Eliot, Pierre Reverdy o Garcilaso son repuestas a las preguntas que se hizo sobre sí mismo y sobre su trabajo como creador.

En ese sentido, lo que Cernuda encontró en la línea trazada por Campoamor fue un ámbito literario en el que enmarcar su propia obra. No sólo se trataba de iniciar un camino poético, sino de encajarlo en la tradición

\footnotetext{
13 Cfr. Prosa II, ed. cit., p. 54.
} 
hispánica. Así, al menos, se deduce de sus palabras en «Tres poetas clásicos»:

Gracias a Garcilaso los poetas más opuestos y diferentes, un Aldana y un Góngora, encontraron su propio camino; gracias a él pudo existir la obra de un Francisco de la Torre, un Francisco de Rioja. Sin esa tradición, que Garcilaso instaura en la mañana de nuestro Renacimiento, mucha hermosa parte de la lírica española no hubiera hallado base sobre la cual asentarse. Porque hay dos tipos de poetas: el poeta que crea su propia tradición, como Garcilaso, y el poeta que refina lo ya creado por otros, como Herrera. $(P I, 489)^{14}$

También él mismo se consideró creador de una nueva tradición en la poesía española, y de ahí su voluntad de subrayar hallazgos como el poema extenso, que consideraba ajeno a la tradición hispánica, el monólogo dramático o su peculiar sentido del lenguaje literario. Aún así, Cernuda pretendió que esa originalidad tuviera su asiento en la tradición hispánica, como en 1961 señalaba Fernando Charry Lara: «Dentro de la poesía española tradicional adivinamos la obra de Cernuda en una línea en la que la delicadeza de la expresión está simultáneamente alentada por la llama de la emoción y por la austeridad del pensamiento» ${ }^{15}$. Algo similar repetía José Emilio Pacheco en 1963 desde la páginas de la Revista Mexicana de Literatura:

...es imposible negar cuán necesaria y saludable, para él y para la poesía castellana, fue la reacción de Cernuda contra lo folklórico y lo «pedantesco,» contra lo bonito y la finura, a la que opuso - fincado en Manrique, Aldana, Bécquer, los románticos ingleses $\mathrm{y}$, al menos en un época, Leopardi- una tendencia a la objetividad, al empleo preciso del lenguaje hablado y el tono coloquial ${ }^{16}$.

Esa tradición, que empezó a definir en torno a 1941, se abría para Cernuda con Jorge Manrique y seguía, a través de Garcilaso, Aldana o san Juan, hasta la poesía de Gustavo Adolfo Bécquer. Con esta reconstrucción intencionada de la historia de la poesía en España, Cernuda buscaba una tradición que justificara su propio espacio como escritor y en la que él

14 Lo mismo repitió respecto a Bécquer en sus Estudios sobre poesía española contemporánea: «Bécquer desempeña en nuestra poesía moderna un papel equivalente al de Garcilaso en nuestra poesía clásica: el de crear una nueva tradición» (Ibid., p 97).

15 «Luis Cernuda», en HARRIS, Derek (ed.), Luis Cernuda, ed. cit., p. 66.

16 «Grandeza y soledad de Luis Cernuda», Revista Mexicana de Literatura 7-8 (1963), p. 55. Pacheco parafrasea los párrafos de Historial de un libro en los que Cernuda se refiere al cambio que para su tono poético significó su estancia en Inglaterra: «Aprendí a evitar, en la medida de lo posible, dos vicios literarios que en inglés se conocen, uno, como pathetic fallacy...; otro, como purple patch o trozo de bravura, la bonitura y lo superfino de la expresión» (Prosa I, ed. cit, p. 646). 
debía ser, como Garcilaso o Bécquer en su momento, punto final y renovación.

El recorrido que hemos trazado a lo largo de la obra crítica de Luis Cernuda tenía como objetivos precisar el momento en que el poeta empezó a preocuparse por la lengua poética, con consecuencias determinantes en su obra, y analizar la importancia que el estudio de la historia de la poesía española tuvo en ese cambio de rumbo. El gusto por un lenguaje sencillo y buscadamente conversacional, que puede seguirse a partir de Como quien espera el Alba, tuvo su origen en ese proceso de reflexión que se inició con su carrera docente en Inglaterra, centrada en la historia de la literatura española. La aspiración de Luis Cernuda, al menos a partir de esas fechas, fue crear una poesía en la que el lenguaje y la retórica no se interpusieran entre el texto y el lector. Probablemente fue esto lo que consideró como poesía popular, es decir, una poesía inserta en la historia, atenta a la realidad de las cosas y escrita en el lenguaje vivo de los hombres. Hasta 1940 Cernuda fue un poeta en ciernes, y, como tal, pasó por diversas etapas e influencias (Guillén, Reverdy, Juan Ramón Jiménez, Mallarmé, Garcilaso, Bécquer, el surrealismo o Hölderlin). Posiblemente sea en ese período, como Octavio Paz o Tomás Segovia pretendían, donde se oiga su voz más intensa como poeta; pero lo cierto es que fue a partir de 1940 cuando comenzó una intensa reflexión sobre su propia obra y sobre la lengua poética que le condujo a ser el poeta que terminó siendo y el que quiso ser, el de Con las Horas contadas o el de Desolación de la Quimera. 